\section{Books and Monographs}

Blood Groups in Man. 5th ed. By R. R. Race and Ruth Sanger. (Pp. xxviii +599 ; illustrated + tables. 110s.) Oxford: Blackwell Scientific Publications. 1968.

Race and Sanger's book on Blood Groups in Man was first published in 1950 and is now coming out in its fifth edition in English, besides other editions which appeared in Spanish and German. In 1950 Sir Ronald Fisher wrote in the foreword that he was glad that Race and Sanger had been induced to undertake the heavy labour of preparing a modern book on the blood groups giving 'special attention to inheritance'. The fact that it is now possible even to think of blood groups without relating them to genetics indicates the development of the past 18 years in which Race and Sanger's work has played such an important part. In the present edition they state that while in 1950 the title 'Blood Groups' seemed appropriate for a book dealing almost entirely with antigens of the red cells, they have felt for some years that they owe an apology to those other inherited factors found in blood, the various haemoglobins, serum groups, the enzyme variants, and to the so 'splendidly complicated' antigens of the white cells. The reader, however, will be grateful that they have kept to what one might call classical blood groups and not let their book overflow into an indeterminate compendium.

One of the recent exciting developments is the finding that one of the blood groups, $\mathrm{Xg}$, is linked with the $\mathrm{X}$ chromosome, just as haemophilia and other $\mathrm{X}$-linked characters. This makes it necessary for the authors to discuss chromosomes at some length, and on page 552 of this book there is a tentative map of the human $\mathrm{X}$ chromosome, probably of the short arm. On it are found the loci for the blood groups $\mathrm{Xg}$, ichthysosis, ocular albinism, deuteran, glucose-6-phosphate-dehydrogenase, protan, and haemophilia. The distance between the various loci are given in centimorgans. There cannot be many books of this kind first published 18 years ago and still maintained by the same authors, which have so much of the original enthusiasm still in them. The authors and the publishers both have to be congratulated on the appearance of this book in its fifth edition.

H. LEHMANN

The Congenital Methemoglobinemias. Physiology and Pathophysiology of the Methemo- globin Metabolism. Bibliotheca Haematologica No. 28. By Otmar Tönz. (Pp. $v+146 ; 26$ figures + 6 tables. sFr./DM. 39. \$9.35. 78s.) Basel/New York: S. Karger; London: Academic Press. 1968.

This monograph deals with two groups of rare hereditary conditions which result in increased methaemoglobin levels and persistent cyanosis, namely $\mathrm{Hb}-\mathrm{M}$ disease and enzymopenic methaemoglobinaemia.

$\mathrm{Hb}-\mathrm{M}$ disease was first described by Hörlein and Weber in 1947 and 1948 as a type of familial methaemoglobinaemia characterized by dominant inheritance. Other families have subsequently been discovered in various parts of the world, and it is now known that at least five different molecular species of $\mathrm{Hb}-\mathrm{M}$ exist, i.e. Hb-M Boston, Saskatoon, Iwate, Hyde Park, and Milwaukee: two of the haemoglobins have substitutions in the $\alpha$ chain and three in the $\beta$ chain. Other possibly distinct types await exact analysis. It is suggested that the substitution of a larger amino acid for histidine or valine leads to a complex forming between trivalent haem iron and the reactive side chain of the amino acid, which constitutes an 'internal ligand'. This complexing of the trivalent iron probably explains its resistance to reduction by reducing agents. As in other haemoglobinopathies, the amount of abnormal component formed is smaller than the theoretically expected $50 \%$ : in $\mathrm{Hb}-\mathrm{M}$ disease it has been reported to vary between $20-30 \%$. Homozygosity has not been observed, and it is likely that the occurrence would be lethal, at least in the case of $\alpha$ chain substitutions. Dr. Tönz discusses the fact that in several cases $\mathrm{Hb}-\mathrm{M}$ has been apparently absent in both parents of the propositus, and speculates on the possibility of a relatively high mutation rate. Clinically, affected patients have life-long cyanosis but without impairment of physical capacity or apparent fertility.

Congenital enzymopenic methaemoglobinaemia was shown to be based on an enzyme defect for the first time by Q.H. Gibson in 1948-the enzyme concerned is NADH diaphorase. Most of the affected families have been of European ancestry, though 13 families have been observed in Eskimos and Alaska Indians. In contrast to the $\mathrm{Hb}-\mathrm{M}$ diseases, the typical enzymopenic type is inherited as an autosomal recessive. (Rare dominant forms possibly exist.) Presumed heterozygotes have no symptoms and have normal methaemoglobin levels in their blood. However, measurement of the rate of methaemoglobin reduction and enzyme assays give values for heterozygotes intermediate between the normal and the very low values observed in 
clinically affected homozygotes. In contrast to the sex-linked G6PD deficiency, morphological studies of red cells show that the defect in heterozygotes for enzymopenic methaemoglobinaemia is distributed diffusely in the red cell population, which is in keeping with autosomal inheritance.

In summary, Dr. Tönz's monograph is a valuable addition to medical and genetic literature; it is excellently organized and illustrated, and the translation into English, though not entirely free from blemishes, has been well done on the whole.

\section{J. V. DACIE}

An Atlas of Mammalian Chromosomes. Vol. 2. By T. C. Hsu and Kurt Benirschke. (Pp. xx+200; 50 plates. Loose-leaf boxed. DM. 37.60. \$9.40.) Berlin: Springer. 1968.

The second volume of this excellent atlas has now appeared, and in many ways is an improvement on the first. I still have two major points of criticism. First, that it would be most desirable and in line with zoological practice to give authorities for specific names. Second, and I think more important, the authors should stop using a variety of terms to describe the chromosomes, including terms of such doubtful validity as 'subtelocentric', 'subacrocentric'-what do these mean? A telocentric chromosome strictly has no short arms and a completely terminal centromere, and it is questionable whether such chromosomes really exist. Does a subtelocentric have less than no short arms? This is of course absurd, but I use it to illustrate the problems.

In a recent apologia in the Mammalian Chromosome Newsletter (Vol. 9, No. 4, September, 1968) Dr. Hsu recognizes both these problems. The first was apparently taken as a calculated risk; the calculation has not come off, so could we have the authorities for each proper name please! The second, Hsu agrees that there are problems with the terms used, and that these are both subjective and inaccurate; surely, therefore, the answer is not to continue to use all the terms available indiscriminately but to choose which terms are best and accurate, define them, and stick to them. Surely three are sufficient to describe chromosome morphology, especially when the karyotype is given for each species: these are 'acrocentric', 'submetacentric', and 'metacentric'. All the others are superfluous.

The cumulative index given in the present volume will be of great value as it builds up, and the authors are to be commended on the clearer and more uniform reproductions in the present volume. If future volumes continue to improve at the same rate, the final publication should be of great value to all mammalian cytogeneticists.

JOHN L. HAMERTON

Primer of Chromosome Practice. Plant and Animal Chromosomes Under the Microscope. By G. Haskell and A. B. Wills. (Pp. xv +180 ; illus- trated + tables. 37s. 6d.) Edinburgh: Oliver \& Boyd.

This little book is aimed primarily at students and teachers of biology requiring a brief and simple text on methods of chromosome analysis. The first part covers the essential theoretical background to plant and animal cytogenetics, the second part the various aspects of cytological techniques, and the third part some essentials of data presentation. It seems a great pity even in such an elementary handbook as this that only very brief mention is made to the techniques in common use today for the study of human and mammalian chromosomes, particularly as more workers are perhaps engaged in this field than even in the study of plant chromosomes.

Plates are generally not up to the standard which is expected with modern microscope and photographic methods. The book may be useful as an introductory manual for some biology students and teachers; it could, however, have been made much more useful.

JOHN L. HAMERTON

Elements of Medical Genetics. By Alan E. $H$. Emery. (Pp. ix $+247 ; 44$ figures + tables. 35s.) Edinburgh: E. \& S. Livingstone. 1968.

Professor Alan Emery's short book on the elements of medical genetics follows a logical order, with chapters on history, the chemical basis of inheritance, chromosomes and chromosomal abnormalities, developmental genetics, inheritance in families, genetic factors in some common diseases, pharmacogenetics, population genetics and natural selection, radiation and human heredity, and genetics and the physician. It is clearly and simply written. New terms are well defined as they are introduced. The illustrations are by clear line diagrams. There is a good glossary. At the end of each chapter there are selected recommendations for further reading. Noteworthy chapters are those on pharmacogenetics, radiation genetics, and developmental genetics.

There are two aspects of the work, which might perhaps be improved in later editions. First, in the effort to avoid technicalities, some of the clinical examples are oversimplified. For example phenylketonuria is not (and must not be) treated by a diet containing no phenylalanine; porphyria is not a single entity; the site of coarctation of the aorta is not just after the main artery of the body leaves the heart; pyloric stenosis was not 'invariably' fatal until 1912. Second, some of the more difficult genetical concepts are perhaps treated too simply. The important concept of heritability is rightly introduced in the chapter on common diseases, but the earlier account of polygenic inheritance is probably insufficient to make this section on heritability readily intelligible.

This introduction will certainly stimulate many medical students to take an interest in genetics, and to realize that the relevance of genetics is not only to rare mendelian and chromosome abnormalities. The book should also appeal to a wider audience, including nurses and social workers.

C. O. Carter 